\title{
Evaluation of energy saving potentials, costs and uncertainties in the chemical industry in Germany
}

Bühler, Fabian; Guminski, Andrej; Gruber, Anna; Nguyen, Tuong-Van; von Roon, Serafin; Elmegaard, Brian

Published in:

Applied Energy

Link to article, DOI:

10.1016/j.apenergy.2018.07.045

Publication date:

2018

Document Version

Peer reviewed version

Link back to DTU Orbit

Citation (APA):

Bühler, F., Guminski, A., Gruber, A., Nguyen, T-V., von Roon, S., \& Elmegaard, B. (2018). Evaluation of energy saving potentials, costs and uncertainties in the chemical industry in Germany. Applied Energy, 228, 2037-2049. https://doi.org/10.1016/j.apenergy.2018.07.045

\section{General rights}

Copyright and moral rights for the publications made accessible in the public portal are retained by the authors and/or other copyright owners and it is a condition of accessing publications that users recognise and abide by the legal requirements associated with these rights.

- Users may download and print one copy of any publication from the public portal for the purpose of private study or research.

- You may not further distribute the material or use it for any profit-making activity or commercial gain

- You may freely distribute the URL identifying the publication in the public portal 


\title{
Evaluation of Energy Saving Potentials, Costs and Uncertainties in the Chemical Industry in Germany
}

\author{
Fabian Bühler $^{a, *}$, Andrej Guminski ${ }^{b}$, Anna Gruber ${ }^{b}$, Tuong-Van Nguyen ${ }^{a}$, Serafin \\ von Roon ${ }^{b}$ and Brian Elmegaard ${ }^{a}$ \\ ${ }^{a}$ Technical University of Denmark, Department of Mechanical Engineering, Nils Koppels Allé, Building \\ 403, 2800 Kgs. Lyngby, Denmark. \\ ${ }^{b}$ Forschungsgesellschaft für Energiewirtschaft mbH, Am Blütenanger 71, 80995 München, Germany.
}

\begin{abstract}
In $2014,19.3 \%$ of Germany's industrial final energy consumption could be allocated to the chemical industry. Energy efficiency measures with focus on the chemical industry could thus contribute to reaching the German goal of reducing greenhouse gas emissions. To achieve this goal, energy planners and industries alike require an overview of the existing energy efficiency measures, their technical potential as well as the costs for realizing this potential. Energy efficiency opportunities are commonly presented in marginal cost curves, which rank these measures according to specific implementation costs. Existing analyses, however, do not take uncertainties in costs and potentials sufficiently into account. The aim of this paper is to create a marginal cost curve of energy efficiency measures for the chemical industry in Germany, while quantifying the uncertainties of the results and identifying the most influential input parameters. The identification of energy efficiency measures and the quantification of the associated technical potentials and costs were identified based on literature data and own assessments. Based on these findings a cost curve was created for the current technical potential. This potential was found to be 24.4 PJ per year, of which 23 PJ had negative lifetime costs. To investigate the uncertainties of these results, Monte Carlo simulations were performed to quantify the standard deviations of the implementation potential and costs. Furthermore, a sensitivity analysis, based on Morris Screening and linear regression, was conducted in order to identify the most influential model input parameters. With the applied approach, it was shown that uncertainties have a non-negligible impact on the final energy saving potential and costs, as well as the shape of marginal cost curves. The standard deviation of the energy saving potential was found to be 3.1 PJ. Furthermore, it is possible to systematically prioritise efforts in refining data.
\end{abstract}

Keywords:

Energy efficiency, Chemical industry, Marginal cost curve, Uncertainty analysis, Sensitivity analysis.

\section{Introduction}

$19.3 \%$ of the industrial final energy consumption in Germany was used in the basic chemical industry in 2014 [1]. For the year 2014 the annual energy-related greenhouse gas (GHG) emissions were approximately $48.2 \mathrm{Mt} \mathrm{CO}_{2}$ eq. [2]. GHG abatement measures with focus on the chemical industry, could thus contribute significantly to reaching the German goal of reducing these emissions by $55 \%$ in 2030 compared to 1990 [3]. To achieve this ambitious goal, the quantification of abatement opportunities and their individual costs has great significance for energy planners, industries and governmental institutions. In addition, a robust representation of the industrial sector in national or regional energy system models is needed to obtain accurate results for scenario analyses and forecasts. A detailed analysis of the German industry as a whole was performed by Fleiter et al. [4]. The authors first distributed the final energy consumption and GHG emissions of the industry to different subsectors. Then, a variety of scenarios showing the energy and GHG reduction potential were calculated for the largest industrial sectors. The chemical industry in Germany was described in detail including the main basic chemicals. The results showed a technical potential for a reduction in final energy consumption of $14 \%$ until the year 2035 with respect to the base year 2007. Furthermore, the

\footnotetext{
* Principal corresponding author. Tel.: +45 45254102

Email address: fabuhl@ mek.dtu.dk (Fabian Bühler)
} 
study elaborated that most measures are economically feasible. The economic potential was only $1 \%-$ point lower than the total technical potential. Recently Griffin et al. [5] analysed the potential for energy demand and carbon emission reduction in the U.K. chemical sector. They showed that current technologies are expected to provide short-term energy savings, while more innovative technologies are found to be very speculative. As a result, the transition pathway to a low carbon future in the UK is subject to large uncertainties.

Brunke [6] developed a techno-economic method to analyse energy efficiency measures on a plant level and applied this method to several energy intense processes. The impact of discount rate, energy price increase and costs of $\mathrm{CO}_{2}$-certificates on the economic energy efficiency potentials was performed as part of this work by means of a One Factor a Time sensitivity analysis. he results of this sensitivity analysis were further shown in cost curves for energy savings in Germany.

Saygin et al. [7] analysed the impact of uncertainties in final energy consumption and production data on long term energy efficiency assessments. The paper provided a detailed analysis of the basic chemical industry in Germany. The analysis quantified the annual energy efficiency improvements. Limits of the calculations, due to the availability of final energy consumption and production data, were further discussed.

For the ammonia production in particular, Rafiqul et al. [8] performed an analysis of energy efficiency improvement potentials, where uncertainties were included in the modelling approach. It was found that uncertainties have a considerable effect on the outcomes. The applicability of efficiency measures to factories, meaning the number of sites where a specific measure can be implemented, adds great uncertainty to the overall efficiency potential. However, it was found to have less effect on the comparison of different policies and price scenarios. The authors further highlighted the uncertainty of energy prices, which have been volatile in the past and are difficult to predict for the future.

With respect to uncertainty analysis, Tran et al. [9] applied the Monte Carlo approach to show how uncertainties in input data can impact the results of electricity generation costs of different emerging renewable energy technologies. Di Lullo et al. [10] performed uncertainty analysis of GHG emissions from well-to-tank and combustion of transportation fuels. Using Monte Carlo simulations, the uncertainty of different fuels were established and compared using box plots.

For the shipping industry, $\mathrm{CO}_{2}$ reduction potentials were quantified by Yuan et al. [11]. The study included the uncertainties of the single measures and found the uncertainty of the total emission reduction using the Monte Carlo method. Marginal abatement cost curves were used to show the results and represent the uncertainties. The work showed the importance of considering the uncertainties as otherwise the ranking results may be misleading. This study was thus followed up [12] to include a ranking algorithm which included uncertainties and allowed to decide between costs and abatement of the measures.

While these works are very relevant to provide complete information to e.g. policy makers on which opportunities to target, they do not identify the required precision of data and which data needs to be collected in the first place.

An analysis of energy efficiency opportunities in the German pulp and paper industry is found in Fleiter et al. [13]. This study is highly relevant for the current work. The authors determined energy use on a process level and established 17 energy efficiency measures. Several scenarios for the implementation until 2035 were analysed and a sensitivity analysis for the $\mathrm{CO}_{2}$ Abatement Cost Curve was created. The sensitivity analysis took the discount rate and the selected year of implementation into account by varying one factor a time and showing the cost curves for energy savings for each sensitivity action. A higher discount rate increased the costs, whereas selecting an implementation year that lied further in the future increased the potential and reduced the costs of the implementation of energy saving measures. This was due to technology diffusion, which was explicitly included in the model and represented the technology readiness over time. Moret et al. [14] proposed a method for defining input uncertainties to energy planning models, for which probability distributions for input parameters are often limitedly included. The method was applied to a national model performing a global sensitivity analysis. In order to determine the influential factors, the 
elementary effect method was chosen, as it has a higher computational efficiency towards calculating the total effect sensitivity index. Both measure sensitivity across the whole input space, while the elementary effect method is a screening the other is variance based.

With respect to uncertainty analysis, several articles used the Monte Carlo (MC) procedure with different sampling strategies. Deng et al. [15] analysed cost savings in energy performance contracting, using the energy price and energy conservation performance as the main factors. The uncertainties of $\mathrm{CO}_{2}$ savings in demand side response programmes were found using Monte Carlo simulations with 100 random samples [16]. On a production system level, different methods were developed to include uncertainties in e.g. multi-decision models for ethylene production [17], in which the authors used fuzzy data to evaluate and analyse different energy efficiency situations.

Marginal cost curves (MCC) are a visualization tool, which allows for the concise representation of the results of numerous individual economic analyses. Similar analyses have been performed in several studies [4,6,18-20] which are shortly introduced in the following. Fleiter et al. [4] created MCCs for fuel savings and GHG emission reduction in the German industry. Brunke analysed energy intense production processes and showed the energy saving potential and costs in MCC [6]. Some parameters were varied as part of a one-factor a time analysis, to study their impact on the potential. In the study by Nauclér and Enkvist [18] an abatement cost curve for global GHG emissions was presented. A cost optimal energy system achieving $\mathrm{CO}_{2}$ emissions reductions of $80 \%$ for Germany was analysed by Henning and Palzer [19]. Similarly, an analysis of cost effective optimisation of the energy system was done by Gerhardt et al. [20].

Despite the high number of studies that use MCCs to present the results of their analyses, a variety of shortcomings have been identified. At the core of this criticism stands the fact that the explanatory power of MCCs is frequently over-estimated. The apparent simplicity of MCCs results in a tendency to derive quick, but possibly misleading conclusions concerning the "optimal" or "expected" order of implementation of the presented energy saving measure. While MCCs order the measures by cost of implementation, this ranking must not be misinterpreted as the optimal, most probable or suggested order of implementation. Such conclusions are not possible because MCCs only contain a share of the information which is required. MCCs, for instance, do not show aspects such as spatial and temporal dynamics as well as interdependencies of the presented measures. Furthermore, conventional MCCs fail to depict the uncertainties inherent to the presented data. An in-depth discussion of the caveats of MCCs was done by Kesicki and Ekins [21], who highlighted these shortcomings of using marginal abatement curves at the example of the illustration of climate change mitigation options. Several limitations were linked to the static nature of the MCC, which is a useful tool to communicate an overview of the potential of climate change mitigation options and the associated costs of implementation. However it also it fails to address in its method the use of uncertainty analysis. Furthermore, Kesicki [22] combined MCCs with energy system models, thereby overcoming shortcomings such as technological potential, system wide interactions and uncertainties. The author highlighted the importance of conducting an uncertainty analysis for input parameters, such as fuel prices and technological deployment by listing it as an idea for future research.

The sectoral energy analyses are subject to a high degree of uncertainty. This is because these analyses rely on literature data for technological potential and costs, which may vary between sources and is partly based on assumptions. It is further subject to estimates and data are often not fully applicable when generalised across different processes. If expert interviews are used they express the views, experience and assumptions of individuals. In addition the actual implementation of cost-effective energy efficiency measures is subject to several barriers, e.g., hidden costs and lack of information [23] also influencing the uncertainty of the potential and costs. 
The literature review showed that several studies on potentials for energy savings in the industry do not take uncertainties of the input parameters into account sufficiently. Furthermore, sensitivity actions are often not systematically performed and are only applied to some input parameters of special interest. While some works included the uncertainties in marginal cost curves, no sensitivity analyses were performed nor were the changes in rankings visualised. All relevant studies, however, agree, that the inclusion of uncertainties is necessary to obtain the correct conclusions from the analyses.

This work addresses these lacks by including a comprehensive uncertainty and sensitivity analysis of marginal cost curves for industrial energy savings. It was the aim of this paper to mitigate some of the weaknesses of conventional MCCs by including an extensive uncertainty and sensitivity analysis and by transparently discuss the assumptions of the performed calculations as well as the limitations of the approach. Following the proposed systematic approach, it is further possible to get additional insights for the dynamics of the cost curves, meaning changes in the ranking of measures, saving potentials and costs, when uncertainties are included, and ranking for prioritising improvements is used. The work further aims to (i) analyse the chemical industry from an energy perspective, (ii) to quantify the potential for energy efficiency and (iii) to consider uncertainties, and (iv) to identify the most important model parameters. The potential for a reduction in energy use was quantified for the basic chemical industry, and implementation costs for individual measures were determined. This paper focuses on the implementation of measures leading to process and equipment optimisation. Cross sectional technologies (such as pumps, air condition and lightning) and fuel switch measures were not considered, as this work has a focus on measures specific to the chemical industry. These technologies have been considered in other works and are seen as established and matured technologies [24]. This paper is based on a previous contribution from the authors [25], where an analysis of the energy efficiency potentials and uncertainties in the basic chemical industry was conducted. In this paper, the effect of these uncertainties was further quantified using a strict methodical approach and a new representation is proposed. By conducting a sensitivity analysis, the most influential input parameters were identified. The latter were subsequently altered in a SA to show the effect on the model output. Hence, by performing an uncertainty and subsequent SA possible inaccuracies in the underlying data were addressed and the effects on the results were quantified. This increases the interpretability of the results and partially alleviates the shortcomings of the MCC approach.

\section{Method}

In this section, the methods and assumptions used to construct the MCC of energy efficiency measures in the chemical industry are introduced. First, the approach for modelling the final energy consumption in the chemical industry is described. Then, possible measures are determined and the method used to determine specific energy saving potentials and costs for the implementation of selected measures is defined. Ultimately, the methods used in the uncertainty and sensitivity analyses are described.

The overall aim was to construct an MCC of energy efficiency measures for the basic chemical industry in Germany and to quantify the effects of uncertain data and sensitive model results on the order of measures in the MCC. The following steps were performed for the basic chemical industry in Germany

(i) Analysis of the final energy consumption

(ii) Determination of possible energy efficiency measures

(iii) Determination of potential energy savings and the associated implementation costs

(iv) Quantification of the uncertainties of the results and identification of the most important model parameters

\subsection{Energy Modelling of the Chemical Industry}


A top down approach was used to model the final energy consumption in the chemical industry. First, the total final energy consumption for the production of basic chemicals was disaggregated to the sub-sector levels. Then, the energy consumption by product were further split to the production process level. This step was performed for products that can be produced via more than one production route. The resulting energy use by product and production process built the basis for selecting the most energy intensive processes, which were subsequently analysed with regard to potential energy savings. The sub-division was based on literature data such as [4,26-28] and is visualised in Fig. 1.

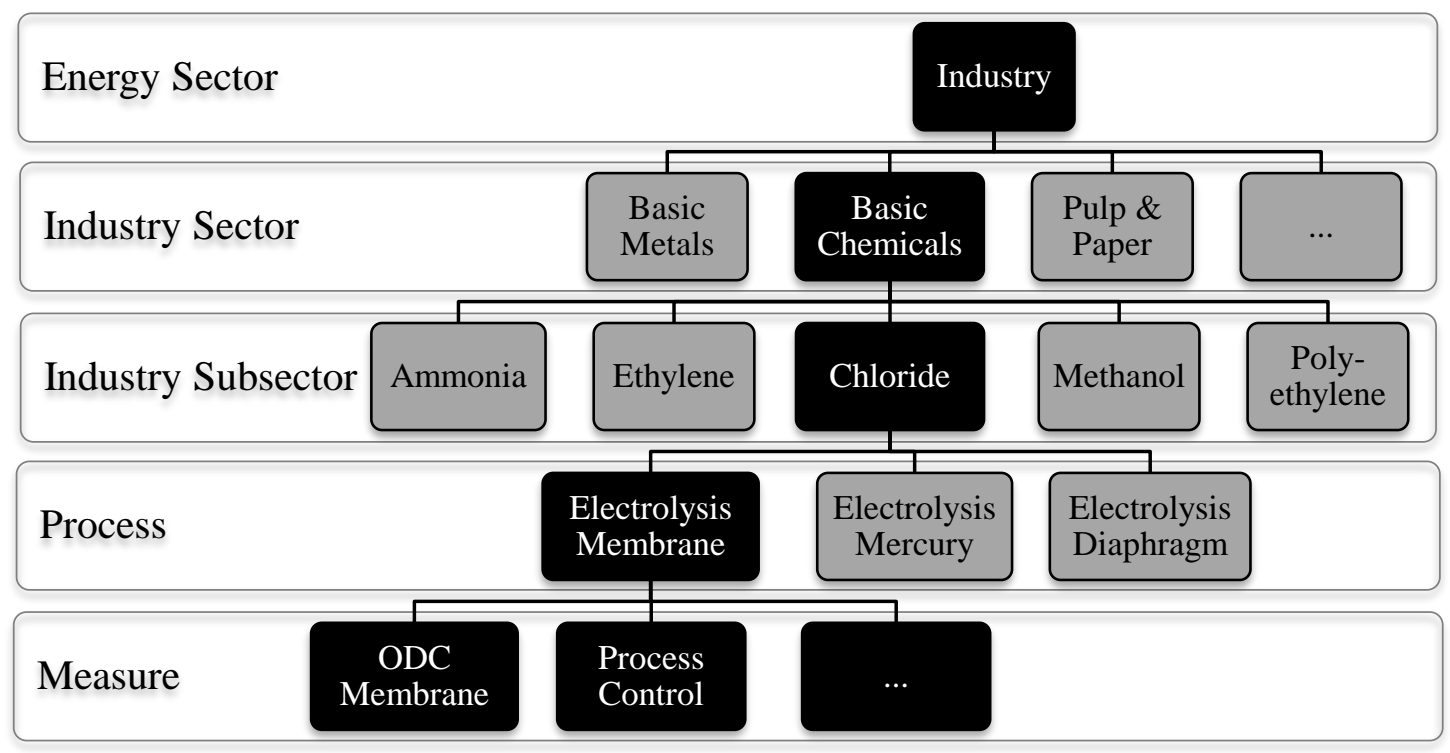

Fig. 1. Overview of the modelling approach for the chemical industry at the example of chloride.

Fig. 2 shows the implementation of energy efficiency measures into the chemical industry. The approach considered both measures which are applicable to the whole subsector and only to specific processes. The aim was further to include the interdependencies amongst the energy efficiency measures on subsector and process levels. Based on the analysis of energy use data in the chemical industry, ammonia, ethylene, methanol, chlorine and polyethylene and the according production processes were considered for further analysis. These products represented $71 \%$ of the final energy consumption in the basic chemical industry in 2012 [1]. Other products had a share of less than $3 \%$ or were disregarded due to the lack of relevant energy saving measures, as in the case of the production of carbon black.

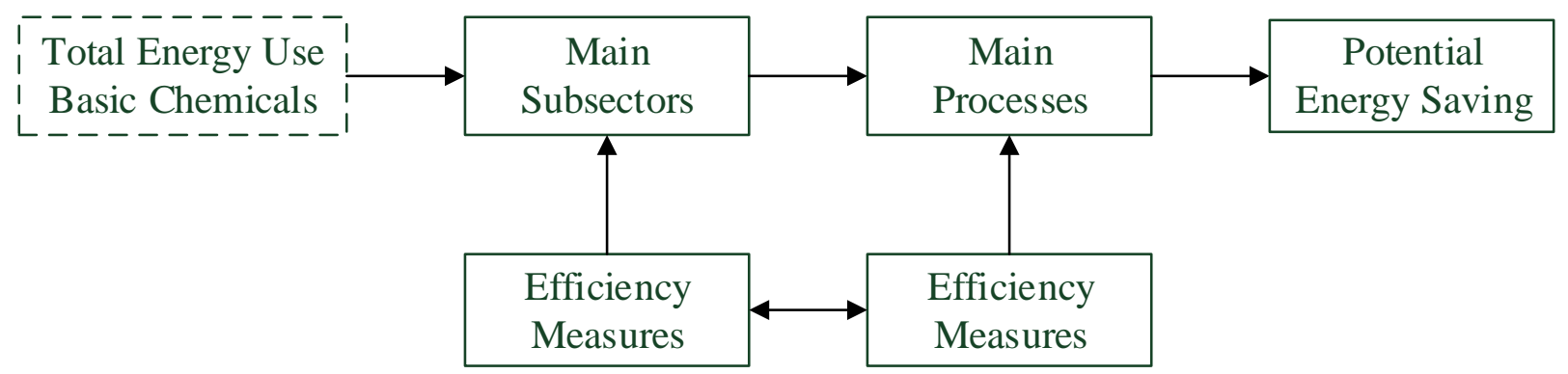

Fig. 2. Overview of the inclusion and interaction of energy efficiency measures in this work.

\subsection{Energy Efficiency Measures}

In the following, the selection and evaluation procedures for energy efficiency measures are described. The most relevant and applicable energy saving measures for the chemical industry in 
Germany were identified based on a literature review and expert assessments. An overview of the measures and the quantification of their potentials and costs can be found in section 3 .

Three types of measures were considered: (i) bundled measures, which can be applied to the entire production site (ii) bundled measures, which can be applied to a specific process or (iii) specific measures with a high implementation potential on the process. In (i) and (ii) several individual measures were combined to form measure bundles. Measures within a bundle might be subject to interdependencies. Because of this simplification, it is possible that not all measures within a bundle can be implemented fully. Furthermore, depending on site-specific parameters, some measures might already be in use. As interdependencies had already been accounted for within the bundle, it was possible to apply them to the complete subsector. Lastly, also specific measures which describe the complete replacement of current production processes were analysed.

\subsubsection{Economic Evaluation of Energy Savings}

All three types of measures were associated with specific energy savings, an applicability factor as well as capital expenditure (CAPEX) and operating expenditure (OPEX). CAPEX were derived from specific investments per energy unit saved or the annual production capacity. CAPEX were annualized using the capital recovery factor, CRF, which was calculated using expression (1). The capital recovery factor takes the expected number of years for the investment, $n$, and the interest rate, $i$, into account. These are set to the investment cycle and $5 \%$, respectively.

$C R F=\frac{\mathrm{i}}{\mathrm{i}-(1+\mathrm{i})^{(-n)}}$

Ultimately, investment costs for measures were corrected for inflation if the year was different than the chosen base year 2007. The energy saving potential and the required CAPEX and OPEX were identified for each measure. Subsequently the potential monetary savings or additional expenses resulting from the implementation of the measure were determined. Savings are based on assuming that heat is supplied by a natural gas boiler. The boiler efficiency, $\eta_{\text {Boiler, }}$ was assumed to be constant at $90 \%$ and the price for natural gas, $c_{\text {gas }}$, was set to $0.025 €$ per $\mathrm{kWh}$ [29]. Annual fuel savings were calculated based on equation (2), where $E_{\text {Saved }}$ is the energy saved due to the implementation of a given measure.

Savings Natural Gas $\left[€\right.$ year $\left.^{-1}\right]=E_{\text {Saved }} \times \frac{1}{\eta_{\text {Boiler }}} \times c_{\text {gas }}$

If the implementation of a measure resulted in electricity savings, an electricity price of $0.05 €$ per $\mathrm{kWh}$ was used [30]. Energy savings and expenses were treated as real annual savings or expenses. It was therefore not necessary to discount the cash flows.

The specific monetary expenses of each measure were calculated using equation (3).

Specific Costs $\left[€ \mathrm{GJ}^{-1}\right]=\frac{\mathrm{CAPEX} \times \mathrm{AF}-(\text { Savings }-\mathrm{OPEX})}{Q_{\text {Saved }}}$

Costs were assessed from a private project cost perspective and were presented as annualized specific savings to allow for comparisons between a heterogeneous set of EEMs and for a given year [21]. The cost perspective affects the interpretability of the results as it defines the considered costing components and the assumed values of these components. The assumed values for the initial investment, O\&M and fuel costs reflect the costs that a company is willing to invest in the respective energy saving (project cost perspective) [21] ${ }^{1}$. It was assumed that the analysed measures are implemented instantaneously. The realized monetary savings and energy efficiency potential consequently do not vary over time.

\footnotetext{
${ }^{1}$ Learning curve effects as well as transaction costs and other non-monetary factors were not considered.
} 
In this paper marginal cost curves were used to compare and contrast the results of economic analyses of energy efficiency measures in the basic chemical industry of Germany. The MCCs constructed in are an adaptation of the concept of conservation supply curves [12].

\subsubsection{System Boundaries and Assumptions}

The analysed systems included processes, which were used to produce the primary products. Processes used to refine the final products as well as by-products were not considered. Furthermore, the measures aimed at reducing the amount of fuel used. If the feedstock was a fuel, as e.g. natural gas in the production of ammonia, it was excluded from the present analysis.

Improvements in cross-sectional technologies, such as compressors, boilers and motors, were not considered.

It was assumed that all process fuels are used to produce process steam in boilers, for which the boiler efficiency was consequently applied. Unit prices for fuels were identical for all sub-sectors and constant over time. The results are not presented separately for electrical energy and fuel savings. However, across all sub-sectors, with the exception of Chlorine, the fuel energy input accounted for the highest share of energy input. In the chlorine production, electricity was the major source of energy.

Furthermore, investment cycles of 20 years and 50 years were assumed for calculating the specific costs of energy efficiency measures and completed changes of the production processes, respectively. These cycles refer to the technical lifetime of the process changes, before replacements are usually considered.

\subsection{Uncertainty and Sensitivity}

The sectoral energy analysis and energy efficiency measures are connected to several sources of uncertainty. Variations of the potential energy savings and the costs of the measures can have a significant impact on the shape of the MCC and were thus analysed in more detail. As this work relied on assumptions and literature data, which vary among sources, quantifying the uncertainty of the results and determining the most important input parameters increase the interpretability of the results.

The uncertainty of the model output was analysed by using the Monte Carlo procedure [31]. This method determines the probability of the model output based on defined uncertainties of the inputs. The procedure has three steps [32]. Firstly, the input uncertainty is defined, secondly the samples for the input uncertainty are created and lastly the samples are propagated through the model to obtain a prediction of the uncertainty. Within the input uncertainty space of dimension $(N$-by- $k)$, random values were generated for each input parameter, where $k$ is the number of parameters and $N$ the number of model evaluations. The sampling of the input space was performed using Latin hypercube sampling (LHS). LHS is an efficient method to produce stable results compared to for example random sampling [33]. Other methods, for instance simple random sampling, can have certain monotonicity conditions, while LHS appears to be a good method to use for selecting values of input variables [34]. The approach of this analysis was based on the work by Sin and Gernaey [35]. The mean, standard deviation and the $95 \%$ percentiles are reported for the results.

In order to identify the most influential model input parameters a sensitivity analysis was performed. Morris Screening [36] was used as a local sensitivity anlaysis in a global context, where one factor is varied and the response of the model output is studied. Linear regression of the MC simulations was additionally used as a global sensitivity analysis to validate the findings. Morris Screening estimates the elementary effects on the model output for all uncertain input parameters. First samples were created using Morris sampling, which replace the initial values in the model. The elementary effects were then determined for each input and the input parameters were ranked according to their mean value and standard deviation. The Morris Screening has three degrees of freedom. The number of levels, $p$, the number of repetitions, $r$, and the perturbation factor, $\Delta$, defining the level of detail [32], which has to be balanced to the computational time required. As the elementary effects are local 
measures, they were calculated at random points in the input space to approximate the distribution of the EE. The mean and standard deviation of these distributions were then used to assess the sensitivity. Type II errors occur when an important elementary effect on the model output is not identified. These errors can be avoided by comparing the estimated mean of the distribution for the absolute values of the elementary effects [37]. This was done by using the absolute mean of the distribution, $\mu^{*}$. The reported screenings used 20 repetitions and 6 levels.

Based on the performed Monte Carlo simulations linear regression was used to summarize the relationships of the parameters as shown in [37]. For the linear regression the Standardized Regression Coefficient (SRC) was used. The SRC can take a value in the interval $[-1,1]$ for each parameter, describing the magnitude of the influence and whether it has a positive or negative effect. The sum of the squared SRC is unity. In order to apply this method, the $R^{2}$ of the linear regression model should be above 0.7 , which indicates that the model could be sufficiently linearized [32].

In order to conduct the uncertainty and sensitivity analyses, the uncertainty input range, as well as its distribution, were defined for each parameter. As described in the previous sections, the main model input parameters for each energy efficiency measure were the energy savings, the applicability to the whole industry, the investment and O\&M costs, as well as the lifetime of the measure. For several measures, the uncertainties were given in the literature or were defined based on variation found in literature values. If this was not possible due to a lack of data, the uncertainty was set to $\pm 15 \%$ for technical parameters and $\pm 20 \%$ for economic parameters as an estimate of general uncertainties. A uniform distribution, $\mathrm{U}$, of the uncertainties was chosen.

\section{Results}

In this section, the results of the analysis are shown. First, the results of the analysis of the chemical industry will be shown, including the description and quantification of energy efficiency measures. Based on this analysis the cumulated results for each chemical and the sector as a whole are presented. A more detailed analysis of the measures is presented in section 3.3, where the MCC for energy savings including uncertainties is shown. The results of the sensitivity analysis are presented at the end of the section.

\subsection{Chemical Industry}

In the following, the considered chemical products and production processes are introduced. First, a brief summary of the overall production processes for the given product is provided. Then a description of the selected efficiency measures is presented. Lastly, all parameters describing the efficiency measures are quantified and the uncertainties are stated.

The choice of the chemical products, ammonia, ethylene, polyethylene and chlorine was taken to represent the major fraction energy use in the German chemical industry and have representative processes. As shown in Fig. 3 the basic chemical industry in Germany represents $19 \%$ of the industry final energy consumption. The chemicals responsible for the majority of this share are ethylene, chlorine, carbon black, ammonia and methanol and polymers. Carbon black can be produced efficiently by producing heat and power with the burned fuels [38]. Furthermore, polyethylene is a major product in the polymer section and was thus chosen to represent this product category. 


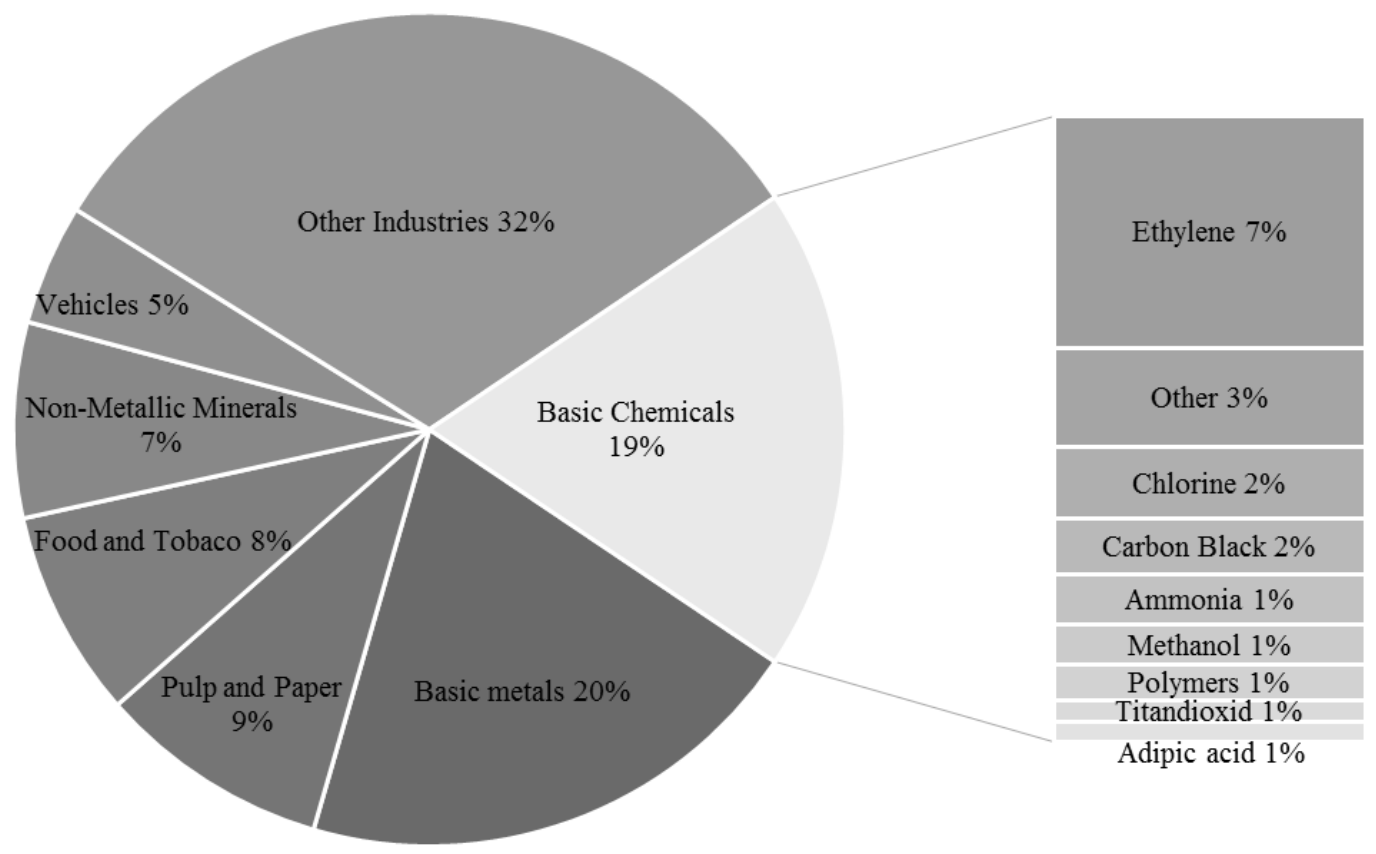

Fig. 3. Overview of the distribution of energy use in the German industry in 2007 based on Fleiter et al. [4].

\subsubsection{Ammonia}

In Germany, Ammonia is primarily produced from natural gas using steam reforming and partial oxidation from other hydrocarbons, in particular heavy fuel oil and distillation residues [4]. In the steam reforming process [39], sulphur is first removed from the natural gas and is then put in a primary reformer where steam is added at high temperature and pressure $\left(700{ }^{\circ} \mathrm{C}\right.$ to $800{ }^{\circ} \mathrm{C}$ at $\left.40 \mathrm{bar}\right)$. In the secondary reformer, air is added to the gas mixture, where the temperature is increased to 1200 ${ }^{\circ} \mathrm{C}$ [6]. The output consists primarily of hydrogen and carbon monoxide. The following water-gas shift transformation takes place at temperatures between $200{ }^{\circ} \mathrm{C}$ and $400{ }^{\circ} \mathrm{C}$, where carbon monoxide and steam are transformed to carbon dioxide and hydrogen. Carbon dioxide is removed in a $\mathrm{CO}_{2-}$ removal process, as the ammonia synthesis only requires hydrogen and nitrogen. The small fraction of remaining carbon dioxide is converted to methane to ensure no carbon dioxide is present to harm the catalysts. After compression of the syngas, the ammonia synthesis takes place, wherein nitrogen and hydrogen react exothermally to ammonia. When using hydrocarbons, other than natural gas, the first reformers are replaced by a gasifier using oxygen as a gasification agent. Sulphur is then removed from the produced syngas. Finally, carbon dioxide is removed and nitrogen is added.

For the production of ammonia, many process specific energy efficiency opportunities are available, of which many were collected in [4] and are available as notes for best available technologies (BAT) in [39] for the case of Germany. Improvements of the reforming process have a high potential to reduce the energy consumption. Possible process improvements are the integration of gas turbines and the replacement of existing gas turbines used to heat the reformer or to preheat the hydrocarbon feed and the combustion air [28]. Overall reformer improvements, such as pre-reforming, rearrangement of convection coils and additional heat transfer surfaces, would increase the reformer efficiency. The shift reaction could be improved by using better and sulphur resistant catalysts, as well as having an isothermal shift reaction. In the $\mathrm{CO}_{2}$ removal section high energy savings can be achieved with advanced solvents, pressure swing absorption or membranes used to efficiently remove $\mathrm{CO}_{2}$ from the synthesis gas [8]. The ammonia synthesis itself could be improved by smaller, better and lower pressure catalysts. Overall measures targeting a higher degree of process integration, improved process control and maintenance can further contribute to reduced energy consumption. In Table 1 an overview of the implemented values for five selected measures is shown. Investments in the reformer are divided into small and large improvements. The first ones require only minor changes 
to the process, e.g. extended preheating of the carbon feed and combustion air or lowering the steam to carbon ratio. Large reformer improvements are for instance the installation of more efficient gas turbines, burner modifications in the reformer, pre-reforming or modified heat recovery coils. These measures were summarised and applied to the German industry in [4]. Energy efficiency measures for ammonia production were further gathered in [8], where they were also used for a scenario analysis for different regions. Further information of these measures are available in the form of BAT suggestions in [40]. The integration of ammonia production, with power generation and nitrogen production is a further option to increase the overall energy efficiency of the system [41].

Table 1. Aggregated and quantified energy efficiency measures with the range of uncertainty for the production of Ammonia, based on references $[4,8,28]$. Own estimates for uncertainty are marked with (*).

\begin{tabular}{llcccc}
\hline & \multicolumn{1}{c}{$\begin{array}{c}\text { Measures } \\
{[-]}\end{array}$} & $\begin{array}{c}\text { Energy Savings } \\
{[\mathrm{GJ} \mathrm{t}]}\end{array}$ & $\begin{array}{c}\text { Applicability } \\
{[\%]}\end{array}$ & $\begin{array}{c}\text { Investment } \\
{\left[€ \mathrm{GJ}^{-1}\right]}\end{array}$ & $\begin{array}{c}\text { O\&M } \\
{\left[€ \mathrm{GJ}^{-1} \mathrm{a}^{-1}\right]}\end{array}$ \\
\hline A1 & Overall Measures & 2.22 & 20 & 10 & $\mathbf{N} / \mathbf{A}$ \\
& & $\mathrm{U}[0.6 ; 3.5]$ & $\mathrm{U}[10 ; 30]$ & $\mathrm{U}[8.5 ; 11.5]$ & \\
A2 & Small Reformer & 1.40 & 20 & 18 & N/A \\
& Improvements & $\mathrm{U}[1.0 ; 1.8]$ & $\mathrm{U}[15 ; 25]^{*}$ & $\mathrm{U}[15 ; 21]$ & \\
A3 & Large Reformer & 4.00 & 10 & 90 & N/A \\
& Improvements & $\mathrm{U}[3.0 ; 5.0]$ & $\mathrm{U}[7 ; 13]^{*}$ & $\mathrm{U}[75 ; 105]$ & \\
A4 & Ammonia Synthesis & 1.00 & $25^{*}$ & 25 & 1 \\
& & $\mathrm{U}[0.5 ; 1.2]^{*}$ & $\mathrm{U}[20 ; 30]^{*}$ & $\mathrm{U}[19 ; 31]^{*}$ & $\mathrm{U}[0.7 ; 1.3]^{*}$ \\
A5 & $\mathrm{CO}_{2}$ Removal & 0.90 & 30 & 15 & 3 \\
& & $\mathrm{U}[0.4 ; 1.4]$ & $\mathrm{U}[28 ; 32]^{*}$ & $\mathrm{U}[10 ; 20]$ & $\mathrm{U}[2.3 ; 3.7]^{*}$ \\
\hline
\end{tabular}

\subsubsection{Ethylene}

Ethylene is produced in the cracking process, where the preheated feedstock is mixed with process steam and cracked at temperatures of around $850{ }^{\circ} \mathrm{C}$ [42]. The resulting gas mixture is quickly cooled down and afterwards fed to low temperature, high-pressure distillation columns. The condensate produced during the cooling processes contains several by-products; aromatics in particular. In Germany the majority of Ethylene is produced with Naphtha as a resource [4].

For the production of Ethylene, three potential energy efficiency measures were identified based on the analysis of [4] and the measures used in [43]. Energy use in steam efficiency opportunities in the steam crackers was analysed in [44] and energy efficiency opportunities were described and quantified in [45] Overall measures include heat recovery and improved process control. Improvements of the steam cracker can result in high savings. Potential measures as part of a revamp of the cracker mentioned in $[44,45]$ include:

- advanced furnace material to reduce coking in the pyrolysis section and thus increasing heat transfer

- improved coating and shapes of tubes and coils can act as catalysts and increase ethylene yields

- integration of gas turbines to produce steam and gas, where combustion gases can be used for preheating the feedstock.

Improving the distillation columns can further reduce the energy input. This could be achieved by Heat Integrated Distillation Columns (HIDiC) and the integration of heat pumps [43-45]. 
Table 2. Aggregated and quantified energy efficiency measures with the range of uncertainty for the production of ethylene, based on references [4,43-45]. Own estimates for uncertainty are marked with (*).

\begin{tabular}{llcccc}
\hline & \multicolumn{1}{c}{$\begin{array}{c}\text { Measures } \\
{[-]}\end{array}$} & $\begin{array}{c}\text { Energy Savings } \\
{\left[\mathrm{GJ} \mathrm{t}^{-1}\right]}\end{array}$ & $\begin{array}{c}\text { Applicability } \\
{[\%]}\end{array}$ & $\begin{array}{c}\text { Investment Costs } \\
{\left[€ \mathrm{GJ}^{-1}\right]}\end{array}$ & $\begin{array}{c}\text { O\&M Costs } \\
{\left[€ \mathrm{GJ}^{-1} \mathrm{a}^{-1}\right]}\end{array}$ \\
\hline E1 & Overall Measures & 0.39 & $20^{*}$ & 9.6 & 1.5 \\
& & $\mathrm{U}[0.28 ; 0.50]^{*}$ & $\mathrm{U}[15 ; 25]^{*}$ & $\mathrm{U}[3.2 ; 16]$ & $\mathrm{U}[0 ; 2]$ \\
E2 & Steam Cracker & 1.14 & 40 & 12 & 5.5 \\
& Optimisation & $\mathrm{U}[0.98 ; 1.3]^{*}$ & $\mathrm{U}[30 ; 50]^{*}$ & $\mathrm{U}[10 ; 14]^{*}$ & $\mathrm{U}[4.7 ; 6.3]^{*}$ \\
E3 & Advanced Distillation & 0.40 & 20 & 17.5 & 2 \\
& columns & $\mathrm{U}[0.3 ; 0.5]^{*}$ & $\mathrm{U}[15 ; 25]^{*}$ & $\mathrm{U}[15 ; 20]^{*}$ & $\mathrm{U}[1.7 ; 2.3]^{*}$ \\
\hline
\end{tabular}

\subsubsection{Methanol}

The production of methanol is similar to ammonia. First, a syngas is produced from natural gas using steam reforming or sludge and other hydrocarbons using partial oxidation. In Germany the majority of the methanol originates from oil-based hydrocarbons [4]. The energy efficiency measures are thus assumed to be the same as for ammonia, as production often occurs in integrated plants. The measures given in Table 1 for ammonia are also used for methanol. Exceptions are improvements in the ammonia synthesis. Some specific energy efficiency improvements, such as integrating heat pumps in distillation columns [46], are possible and can yield low payback times.

\subsubsection{Chlorine}

Chlorine is produced by electrolysis of sodium chloride solution. Different industrial production processes exist. The main production processes are mercury, diaphragm and membrane cell electrolysis [47]. The mercury cell technique is phased out in Germany, due to the high energy use and mercury emissions [4]. Also, the diaphragm cell technique is being converted to the asbestos-free membrane cell technique. An emerging technology is the use of Oxygen-Depolarised Cathodes (ODC) instead of the common metal cathodes in membrane cells [47]. The highest potential for energy efficiency is thus the replacement of old factories using the mercury or diaphragm cell technique to new plants using membranes. It is assumed that all plants will be converted. In addition, the replacement of currently used membranes with ODC or improved membranes can reduce energy consumption in the existing and future plants. As a further measure, the heat recovery and process control of existing plants would lead to further energy savings.

Table 3. Aggregated and quantified energy efficiency measures with the range of uncertainty for the production of Chlorine, based on references $[4,43,47]$. Own estimates for uncertainty are marked with (*).

\begin{tabular}{llcccc}
\hline & $\begin{array}{c}\text { Measures } \\
{[-]}\end{array}$ & $\begin{array}{c}\text { Energy Savings } \\
{\left[\mathrm{GJ} \mathrm{t}^{-1}\right]}\end{array}$ & $\begin{array}{c}\text { Applicability } \\
{[\%]}\end{array}$ & $\begin{array}{c}\text { Investment Costs } \\
{\left[€ \mathrm{GJ}^{-1}\right]}\end{array}$ & $\begin{array}{c}\text { O\&M Costs } \\
{\left[€ \mathrm{GJ}^{-1} \mathrm{a}^{-1}\right]}\end{array}$ \\
\hline C1 & Mercury to & 3.54 & 100 & 225.83 & N/A \\
& Membrane & $\mathrm{U}[3.04 ; 4.04]$ & - & $\mathrm{U}[82 ; 369]$ & \\
C2 & Heat Recovery & 0.12 & 20 & 3.00 & N/A \\
& & $\mathrm{U}[0.10 ; 0.14]^{*}$ & $\mathrm{U}[15 ; 25]^{*}$ & $\mathrm{U}[2.55 ; 3.45]$ & \\
C3 & Process Control & 0.35 & 20 & 20.00 & 2 \\
& & $\mathrm{U}[0.3 ; 0.4]^{*}$ & $\mathrm{U}[15 ; 25]^{*}$ & $\mathrm{U}[17 ; 23]$ & $\mathrm{U}[1.7 ; 2.3]$ \\
C4 & ODC Membrane & 2.97 & 25 & 0.75 & 0.075 \\
& & $\mathrm{U}[2.53 ; 3.42]^{*}$ & $\mathrm{U}[15 ; 25]^{*}$ & $\mathrm{U}[0.64 ; 0.86]$ & $\mathrm{U}[0.064 ; 0.086]$ \\
C5 & Diaphragm to & 0.30 & 100 & 0.75 & N/A \\
& Membrane & $\mathrm{U}[0.25 ; 0.35]^{*}$ & - & $\mathrm{U}[0.64 ; 0.86]$ & \\
C6 & Improved & 0.65 & 100 & 1,230 & N/A \\
& Membrane & $\mathrm{U}[0.55 ; 0.75]^{*}$ & - & $\mathrm{U}[933 ; 1526]$ & \\
\hline
\end{tabular}




\subsubsection{Polyethylene}

Polyethylene is produced from ethylene. Three main products exist: namely high-, low- and linear low-density polyethylene. The polymerisation of the raw material can occur at high pressures, primarily for low-density polyethylene or at low pressures with catalysts. Different types of reactors are used. They can be backmix, fluidised bed, tubular or autoclave reactor. A description of their operation principles was done in [4] and is described in detail as BAT in [48]. Besides waste heat recovery and overall measures including process control, static mixer reactors are seen as having a large potential [43]. Static mixer reactors increase heat and mass transfer during polymerisation by improving mixing during varying flow regimes [49].

Table 4. Aggregated and quantified energy efficiency measures with the range of uncertainty for the production of Polyethylene, based on references [4,43-45]. Own estimates for uncertainty are with a (*).

\begin{tabular}{lccccc}
\hline & $\begin{array}{c}\text { Measures } \\
{[-]}\end{array}$ & $\begin{array}{c}\text { Energy Savings } \\
{\left[\mathrm{GJ} \mathrm{t}^{-1}\right]}\end{array}$ & $\begin{array}{c}\text { Applicability } \\
{[\%]}\end{array}$ & $\begin{array}{c}\text { Investment Costs } \\
{\left[€ \mathrm{GJ}^{-1}\right]}\end{array}$ & $\begin{array}{c}\text { O\&M Costs } \\
{\left[€ \mathrm{GJ}^{-1} \mathrm{a}^{-1}\right]}\end{array}$ \\
\hline P1 & Static Mixer Reactor & 0.67 & 22 & 10 & 1.96 \\
& & $\mathrm{U}[0.49 ; 0.85]$ & $\mathrm{U}[18 ; 26]^{*}$ & $\mathrm{U}[8.5 ; 11.5]^{*}$ & $\mathrm{U}[1.67 ; 2.25]^{*}$ \\
P2 & Overall Measures & 0.05 & 20 & 19 & 2.45 \\
& & $\mathrm{U}[0.04 ; 0.06]$ & $\mathrm{U}[15 ; 25]^{*}$ & $\mathrm{U}[16 ; 22]^{*}$ & $\mathrm{U}[2.08 ; 2.82]^{*}$ \\
P3 & Waste Heat Recovery & 0.07 & 20 & 3 & N/A \\
& & $\mathrm{U}[0.056 ; 0.084]^{*}$ & $\mathrm{U}[15 ; 25]^{*}$ & $\mathrm{U}[2.5 ; 3.5]^{*}$ & \\
\hline
\end{tabular}

\subsection{Energy efficiency in the Chemical Industry}

Based on the total final energy consumption in the chosen sub-sectors for 2007, found in [4], and the potential measures to reduce this consumption as described in Section 3.1, a reduction of 24.4 PJ per year would be possible if all measures were implemented. The total reduction is $7.6 \%$ as shown graphically in Fig. 4. These savings would require investments of almost 2 billion Euro, however most measures can be implemented at negative total costs, which means the measures are profitable. It further shows that additional measures and higher application rates are necessary to reach a significant contribution to the energy saving goals in Germany, if these industries are to contribute significantly. These results are subject to uncertainties, which were analysed in the following for each product and measure.

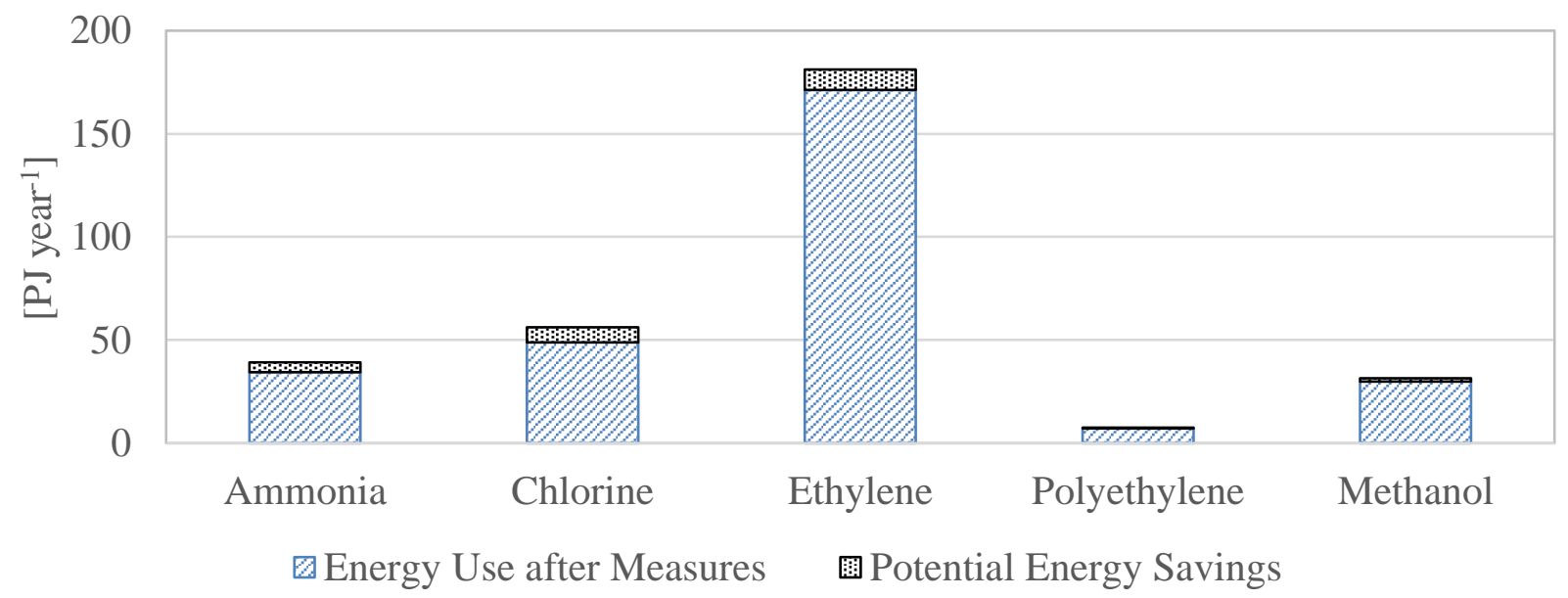

Fig. 4: Energy use and energy saving potential for the analysed sub-sectors in the chemical industry. 
The results in table 5 show that the implementation of measures in the Chlorine production process results in absolute energy savings of more than 7 PJ per year at specific costs of $-6.64 € / G J$. The uncertainty of the energy savings is low, about $6 \%$, as most improvements result from the replacement of old processes with state-of-the-art equipment. These replacements are very likely to happen, as the industry agreed in revamping of mercury and diaphragm plants containing asbestos [4]. The costs, however, are subject to a higher degree of uncertainty. In contrary, the case of Ethylene has a high standard deviation in the energy saving potential and the specific costs. This is amongst other reasons due to the low confidence in the data used for assessing the sectoral savings and costs.

Table 5. Summary of the results for each chemical product with the overall uncertainty (standard deviation) of the investigated model outputs in absolute and relative values.

\begin{tabular}{lrrrr}
\hline \multicolumn{1}{c}{ Industry } & \multicolumn{2}{c}{$\begin{array}{c}\text { Energy Savings } \\
{\left[\mathrm{PJ} \mathrm{year}^{-1}\right]}\end{array}$} & \multicolumn{2}{c}{$\begin{array}{c}\text { Specific Costs } \\
{\left[€ \mathrm{GJ}^{-1}\right]}\end{array}$} \\
\hline Ammonia & 4.81 & $\pm 0.84(17 \%)$ & -4.58 & $\pm 0.81(18 \%)$ \\
Ethylene & 9.70 & $\pm 1.26(13 \%)$ & -2.26 & $\pm 0.78(35 \%)$ \\
Chlorine & 7.34 & $\pm 0.48(7 \%)$ & -6.64 & $\pm 1.81(27 \%)$ \\
Methanol & 2.12 & $\pm 0.47(22 \%)$ & -3.97 & $\pm 0.93(23 \%)$ \\
Polyethylene & 0.47 & $\pm 0.08(17 \%)$ & -4.93 & $\pm 0.69(14 \%)$ \\
\hline
\end{tabular}

\subsection{Marginal Cost Curve}

The MCC for energy efficiency measures in the German chemical industry is shown in Fig. 5. Each block depicted in the MCC represents a specific measure or measure bundle. The specific costs for implementing energy efficiency measures are shown on the ordinate axis. Negative costs imply specific savings; positive values can be interpreted as additional costs imposed due to the implementation of a given measure. The abscissa axis represents the total potential for reducing the energy consumption for a given year. The MCCs consequently show annual costs and potentials of the analysed energy efficiency measures. The width of each block in the MCC is contingent upon the technical energy savings potential and the applicability of a given measure. The MCC in Fig. 5 disaggregates the information presented on the industry-level in Table 5. The mean value and the upper and lower confidence intervals are depicted. Here the confidence interval is defined as the mean value \pm standard deviation, which is found from the Monte Carlo simulations. The potential and specific costs are subject to a high degree of uncertainty, as also seen in Table 5. The changes in the widths and heights of the upper and lower curves indicate the uncertainty. Compared to the mean curve, the order of the measures shown in the upper and lower confidence interval curves varies only slightly. This indicates a relatively constant uncertainty of the individual measures. Compared to the mean curve, the order only changes for three measures in the lower bound scenario and for four measures in the upper bound case. When measures change their position in the lower and upper bound, they do so by only moving up to two places away. 


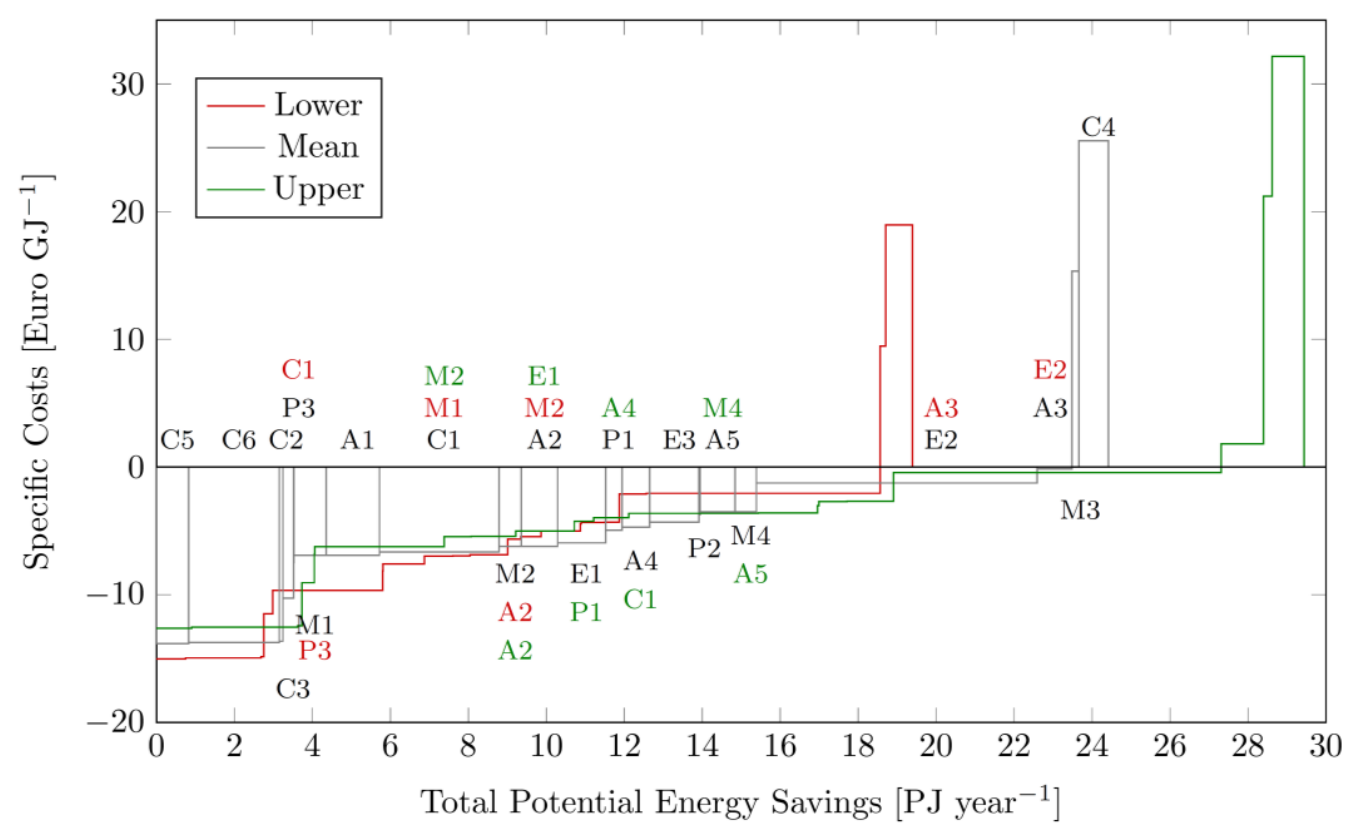

Fig. 5: Marginal Cost Curve of the basic chemical industry with the lower and upper confidence interval. The chosen abbreviated measures given in the figure refer to Table 1-Table 4.

A detailed additional analysis of the measures is shown in Fig. 6, where the cumulated costs of the measures are plotted against the cumulated savings. The order of the energy saving measures is kept constant in the curves for the lower and upper confidence interval and the placement of the measures on those are indicated by the dashed lines. The curve shows that the uncertainties have a relatively small impact on most parts of the curve, as the upper and lower curves are almost parallel to the mean. Measure $\mathrm{C} 1$ and $\mathrm{A} 3$ show relatively high uncertainty compared to the other measures, as the lower and upper curve opens towards $\mathrm{C} 1$ and $\mathrm{A} 3$. Measure $\mathrm{C} 1$ describes the change of the production process for chlorine and measure A3 large improvements of the reformers. Both refer to major production and equipment changes, for which the costs depend on many factors.

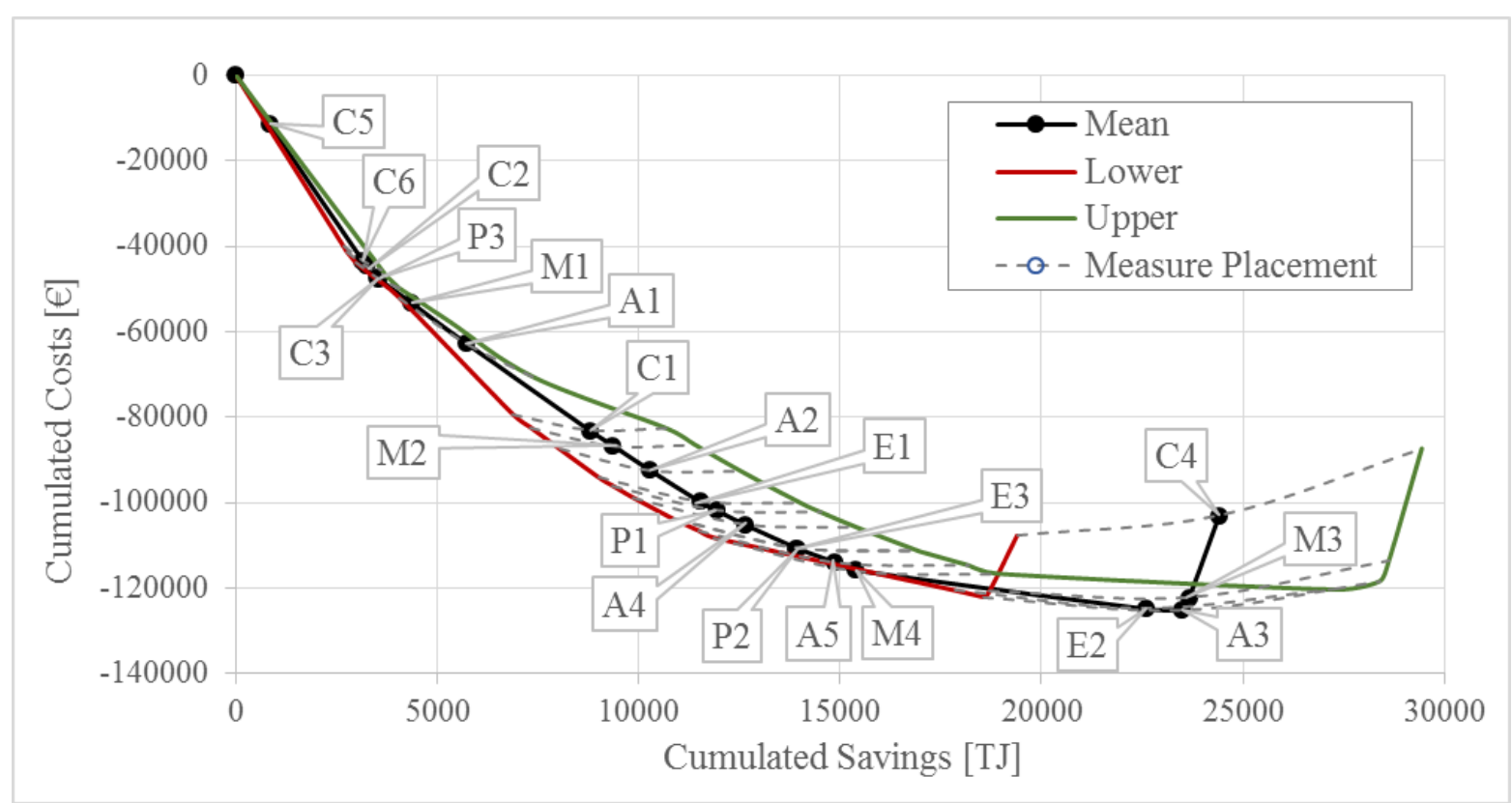

Fig. 6: Cost Curve with the lower and upper confidence interval for the cumulated costs and potentials. The chosen abbreviated measures given in the figure refer to Table 1-Table 4. 
The total annual savings when implementing all measures is equal to the area under the MCC. For all measures, the total savings are 104 million Euro per year with a standard deviation of \pm 20 million Euro. If only measures with negative specific costs are considered, the total savings are 126 million Euro with a standard deviation of \pm 19 million Euro.

\subsection{Sensitivity Analysis}

The sensitivity analysis was performed based on two model outputs. First, the possible annual energy savings were varied. This parameter was selected because it has a high impact on the shape of the MCC. By only considering annual energy savings, the impact of economic parameters was neglected. In order to investigate the impact of energy and economic parameters on the model output, the total possible annual monetary savings were selected as a variable. This model output parameter was the sum of the product of specific costs and annual energy saving potentials for all measures and all subsectors.

The Morris Screening in Fig. 77 was used to identify the input parameters with the highest impact on the energy saving potential of the sub-sectors. The results of the Morris Screening technique were found by comparing the mean and the standard deviations of the distribution function of the elementary effects for each model input parameter [50]. The mean assesses the overall influence of the parameter on the model output, while the standard deviation estimates the ensemble of the higher order effects of the factor due to, i.e. non-linearities and/or interactions with other factors. To improve the interpretability of the outcome, the standard deviation divided by the square root of the repetitions was once added and once subtracted from the mean value, to achieve two lines. The resulting two lines help interpret the results, as only points lying outside of the cone, have a significant influence on the model output. Additionally, the indicator $\mu^{*}$ was used to assess the parameter significance using the Morris Screening. In Table 6 the 10 parameters with the highest effect on the total annual monetary savings are shown. This is useful in order to refine the most important parameters for the energy system model, where a high number of input parameters are present.
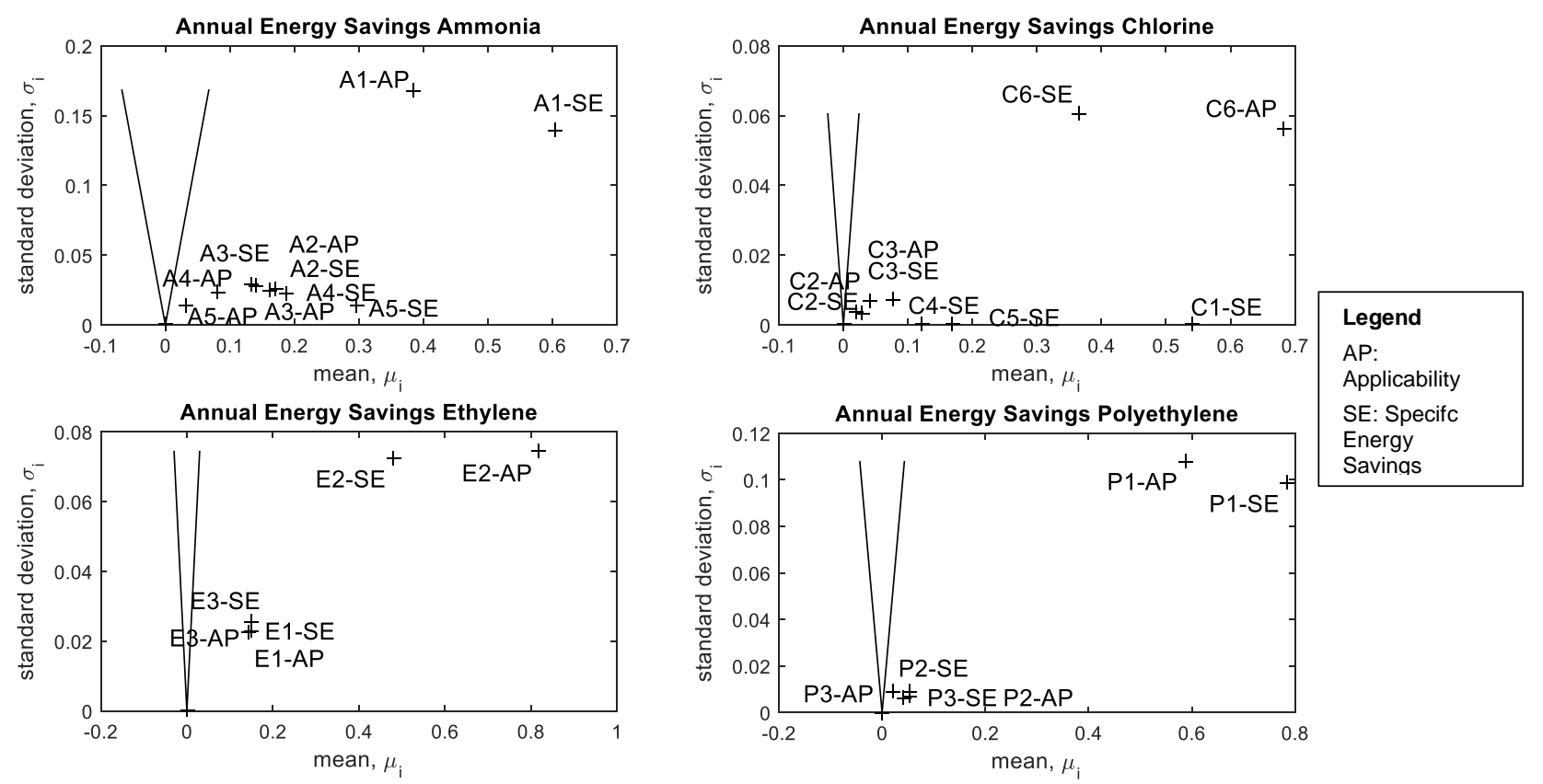

Fig. 7: Sensitivity analysis using Morris Screening for the total annual energy saving potential for each product. The points show the measure from Table 1-Table 4 with the abbreviation of the input parameter found in the legend.

The outcome of the second sensitivity method is shown in Fig. 9. In this figure, the influence of parameters is ranked based on the value of their SRC. The MC model could also be linearized to values of $R^{2}$ above 0.95 for all results, meaning a sufficient degree of linearization was obtained. 
From the Morris Screening in Fig. 7 it is seen that for measures with a high impact, both the applicability and the specific energy savings contribute significantly to a high deviation from the mean. For ammonia production, the applicability and specific energy savings have a high mean for measure A1. The same is observed for other subsectors in measure P1, C6 and E2. This outcome is confirmed in the SRC ranking shown in the graphs on the left hand side of Fig. 9. However, the combination of applicability, AP, and specific energy savings, SE, is not as strict. From both methods it appears that the annual energy savings have one energy saving measure, which has great impact on the results, while many of the other measures have a comparable effect. This means that many measures have a mean and standard deviation of the elementary effects or a SRC of comparable magnitude.

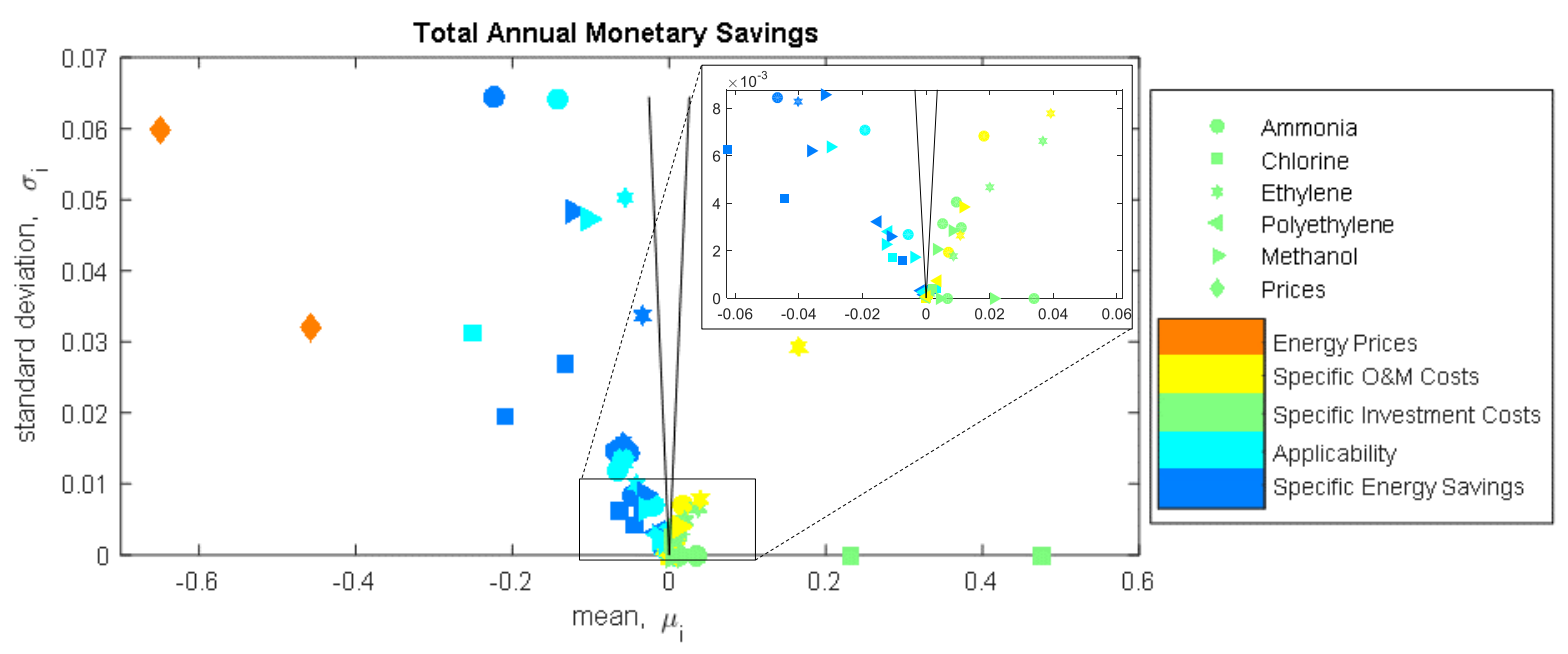

Fig. 8: Sensitivity analysis using Morris Screening of all input parameters on the total annual monetary savings.

Considering the accumulated results across the analysed products and both economic and energy parameters, the dominant input parameters for the uncertainty are shown in Fig. 8 and Table 6 for the Morris Screening and in the graph on the right hand side of Fig. 9. Furthermore, the energy parameters (blue dots) generally have a higher impact on the mean model output. These parameters cause a high standard deviation and have a high impact on the mean value. An exception is the specific investment costs in new factories producing chlorine $(\mathrm{C} 1$ and $\mathrm{C} 4)$, which have a high $\mu^{*}$. These results confirm the observation from the uncertainty analysis of the MCC. The sub-sectors chlorine, ammonia and methanol have the highest impact on the results. However, the majority of the parameters have a small impact on the model output, as they are located around the mean value of 0 . This is shown in the zoomed in part of Fig. 8. Therefore, many of these parameters have a low impact on the standard deviation. This suggests that the model accuracy can be increased by only refining a few influential parameters. As shown in Table 5, the high uncertainty of the specific costs for chlorine is partly caused by savings originating from reduced electricity consumption. In both the Morris Screening and the SRC ranking, the electricity and gas price have a considerable influence on the model output. Based on the outcome of the sensitivity analysis, first the high impact parameters for AP and SE for each subsector should be refined. Measure A1 consists of a bundle of multiple general energy savings, such as process integration and control. Refining this measure will be more challenging than refining for example E2, which targets a specific process within the subsector. Energy prices were found to have a significant impact on the results and should be carefully chosen. As these prices are difficult to predict and volatile, they should be reported as an uncertainty and their impact on the results should be analysed in detail. 
Table 6. Ranking for the estimated sensitivity measure for the Morris screening.

\begin{tabular}{clc}
\hline Rank & Parameter & $\boldsymbol{\mu}^{*}$ \\
\hline 1 & Gas price & 0.65 \\
2 & C1-SC & 0.48 \\
3 & Electricity price & 0.46 \\
4 & C6-AP & 0.25 \\
5 & C4-SC & 0.23 \\
6 & A1-SE & 0.22 \\
7 & C1-SE & 0.21 \\
8 & E2-SOM & 0.16 \\
9 & A1-AP & 0.14 \\
10 & C6-SE & 0.13 \\
\hline
\end{tabular}

By following the approach and methods detailed above, the importance of model input parameters was ranked. The uncertainties of these input parameters can be refined through more detailed analyses. Based on the ranking of the Morris screening, the specific costs of $\mathrm{C} 1$ were identified as important. The uncertainty of this value could be reduced by the collection of additional information through e.g. expert interviews. This allows a targeted increase in the models robustness.
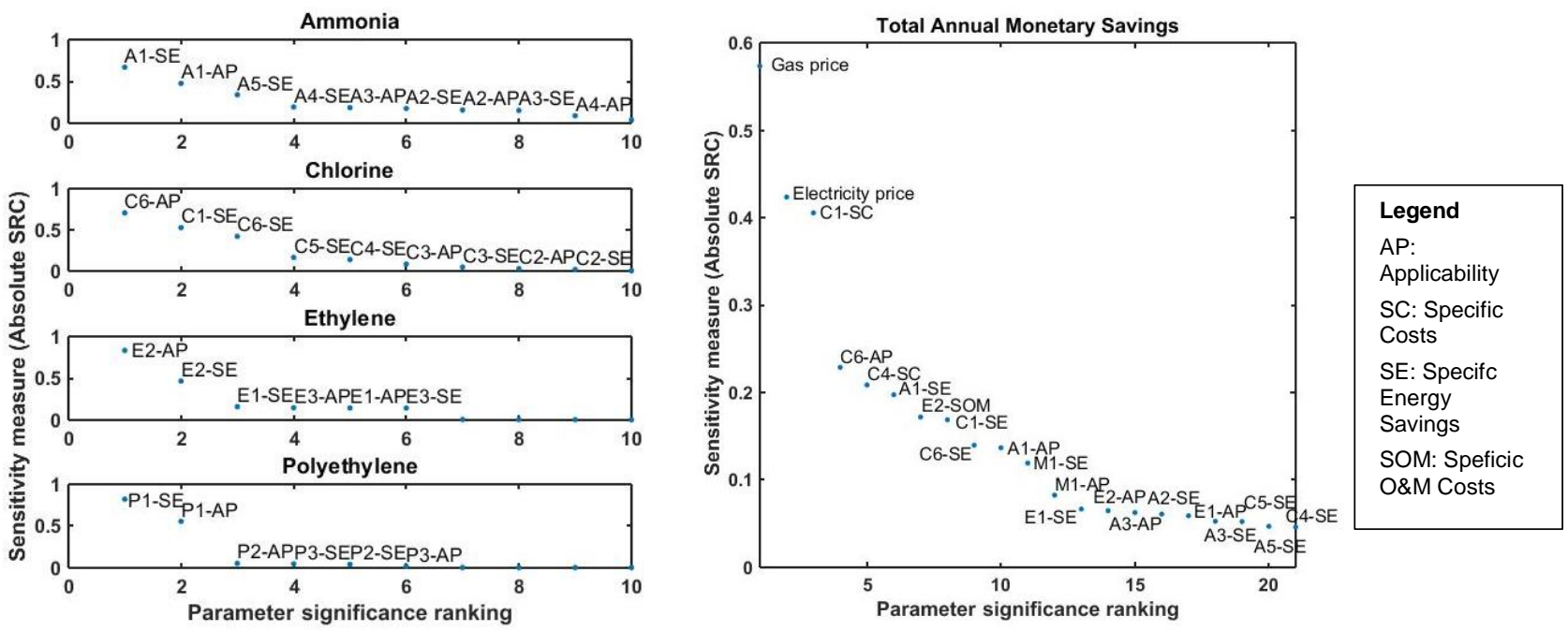

Fig. 9: Sensitivity analysis using linear regression of the annual energy saving potential for each product and the total annual monetary savings. The points show the measure from Table 1-Table 4 with the abbreviation of the input parameter found in the legend.

\section{Discussion}

An account for the uncertainty of the possible energy savings and their costs by Monte Carlo simulations has been performed. The crucial step in analysing the uncertainty of the model output is the definition and quantification of the model input uncertainty range and its distribution. Uncertainties were not quantified for all literature data used in this analysis. The missing uncertainty values were estimated based on a comparison of values reported in the literature and own assessments. It was assumed that all input uncertainty ranges were distributed uniformly. This implies that all values within the upper and lower bound have an equal probability to be chosen. As part of future work a comparison of different distribution functions and their impact on the MCC should be performed. 
Morris Screening is robust to type II errors (identifying a non-important parameter as important) and SRC is the more precise method, if the model is sufficiently linearized. The combination of the two methods thus allows a better interpretation of the model and the ranking of parameters.

The inflexibility of the MCC with respect to uncertainties was overcome in this work. The interactions between individual measures were not present, as the measures chosen were independent of each other. However, if cross-sectoral technologies and additional measures were added, these interactions would have to be studied in detail.

Refining the assumptions should be performed based on the outcome of the sensitivity analysis, better estimating the specific savings obtainable for the most important measures and their applicability to the industry as a whole. In particular, refining the measures in the chlorine, ethylene and ammonia production could increase the overall robustness of the curve with respect to its uncertainties. The specific costs could be refined by including more sources, whereas the applicability requires better investigation of the current situation at factories. The latter might be feasible in the basic chemical industry, where only a few large factories exist, for example 6 ammonia production units and 9 ethylene plants [4]. The number will unlikely be higher for other industrial subsectors. The specific energy savings can be refined by including detailed process models and more detailed information from manufacturers or case studies.

For the production of ammonia other works [8] showed a possible decrease of $11 \%$ in total energy use for the EU. This is very close to the $12 \%$ found in this work, however some of the potentials used in this work were taken from this reference. Brunke [6] analysed the production of ammonia, chlorine and ethylene with a similar approach as in this paper but included more individually listed measures. For ammonia the energy saving potential was found to be approximately 14 PJ compared to nearly 5 PJ in this work. Similarly, the potential for chlorine was found to be around 9 PJ, while this work considered 7 PJ. The lower absolute saving potential found in this work was due to the lower number of measures included. Further, also the bundling of measures tends to an underestimation in the implementation potential. Considering the specific costs the results were however comparable. Most measures had negative costs over the lifetime and ranged for ammonia and chlorine between -10 Euro per GJ and -3 Euro per GJ. Similar, Fleiter et al. [4] found the basic chemical industry in Germany to have energy saving potentials of between $10 \%$ and $20 \%$ until 2035, depending on the process. As the quantification of measures relied on this or identical sources the potential and costs are comparable.

The interest rate used in this work can be seen as low for investments in the industry. Brückner et al. [51] used for instance a rate of $10 \%$. Generally, lower investment horizons than applied in this work were used with these high interest rates. The interest rate was not specifically covered in the sensitivity analysis, but it was represented in the variation of the specific costs. From the sensitivity analysis, it is further apparent that the specific investment costs, and thus the interest rate, do not have a high importance compared to other parameters.

\section{Conclusion}

This work analysed the energy saving opportunities of the chemical industry in Germany, by considering the costs for implementing energy efficiency measures and their potential. The results are shown in marginal cost curves, where the total potential for implementing the measures are shown, sorted in descending order by their specific costs. It was found that the energy saving potentials for the production of chlorine had the lowest lifetime costs, followed by ammonia and methanol. In total more than 23 PJ of energy use could be saved annually. Most of the measures can be implemented with negative specific costs, meaning that over the equipment lifetime, economic savings from a reduction in final energy consumption outweigh the investment and operation costs. As the analysis was based on estimates and aggregated data from the literature and own assessments, the uncertainty of the model outputs was considered. By means of Monte Carlo simulations, the uncertainty for each model output was reported and integrated into the marginal cost curve. The order of measures in the marginal cost curve was relatively robust. This was a result of assuming uniformly distributed 
uncertainties. However, it was found that costs and potentials of several measures can have a high impact on the results. Therefore a sensitivity analysis was performed to identify the most important model input parameters. For this purpose Morris Screening and linear regression were used. It was found that the costs for energy, as well as the specific saving potential and applicability of measures have the highest impact. By quantifying and comparing these impacts across measures and industries, a prioritisation of input parameters can be done, which should be refined by expert interviews or detailed assessments. This is particularly important for measures in the Chlorine and Ammonia industry. The Morris Screening and linear regression analysis further identified the same important input parameters with only small deviations in their order.

\section{Nomenclature}

$\begin{array}{llll}a & \text { lifetime [years] } & k & \text { number of parameters [-] } \\ \Delta & \text { Perturbation factor [-] } & i & \text { interest rate [-] } \\ \eta & \text { efficiency [-] } & I & \text { Investment [€] } \\ E & \text { Energy [TJ] } & & \\ \mu & \text { mean [-] } & p & \text { perturbation [-] } \\ \mu^{*} & \text { mean of absolute values [-] } & Q & \text { heat flow [TJ] } \\ n & \text { duration [years] } & \sigma & \text { standard deviation [-] } \\ N & \text { model evaluations [-] } & & \end{array}$

\section{Abbreviations}

$\begin{array}{ll}\text { AP } & \text { Applicability } \\ \text { CRF } & \text { Capital recovery factor } \\ \text { BAT } & \text { Best available technologies } \\ \text { GHG } & \text { Greenhouse gas } \\ \text { MC } & \text { Monte Carlo } \\ \text { MCC } & \text { Marginal cost curve } \\ \text { N/A } & \text { Not applicable }\end{array}$

O\&M Operation and maintenance

ODC Oxygen-depolarised cathodes

SC Specific costs

SE Specific energy saving

SOM Specific operation \& maintenance

SRC Standardized regression coefficient

U Uniform distribution

\section{References}

[1] Arbeitsgemeinschaft Energiebilanzen e.V. (AGEB), Energiebilanzen der Bundesrepublik Deutschland 1990-2014- Stand: 11.05.2016, Berlin, 2016.

[2] M. Rasch, A. Regett, S. Pichlmaier, J. Conrad, S. Greif, A. Guminksi, et al., Eine anwendungsorientierte Emissionsbilanz, BWK Das Energie-Fachmagazin. 69 (2017) 80-84.

[3] Federal Ministry for the Environment, Nature Conservation, Building and Nuclear Safety, Climate Action Plan 2050, 2016. https://www.bmu.de/fileadmin/Daten_BMU/Pools/Broschueren/klimaschutzplan_2050_en_b f.pdf (accessed June 26, 2018).

[4] T. Fleiter, B. Schlomann, W. Eichhammer, Energy use and CO2-emissions of industrial process technologies - saving potentials, barriers and instruments [In German: Energieverbrauch und $\mathrm{CO} 2$-Emissionen industrieller Prozesstechnologien Einsparpotenziale, Hemmnisse und Instrumente], Fraunhofer Verlag, Stuttgart, 2013.

[5] P.W. Griffin, G.P. Hammond, J.B. Norman, Opportunities for Energy Demand and Carbon Emissions Reduction in the Chemicals Sector, in: Energy Procedia, 2017: pp. 4347-4356. doi:10.1016/j.egypro.2017.03.913.

[6] J.C.U. Brunke, Energy saving potential of energy intense production processes in Germany [In german: Energieeinsparpotenziale von energieintensiven Produktionsprozessen in 
Deutschland], Universität Stuttgart, 2017.

[7] D. Saygin, E. Worrell, C. Tam, N. Trudeau, D.J. Gielen, M. Weiss, et al., Long-term energy efficiency analysis requires solid energy statistics: The case of the German basic chemical industry, Energy. 44 (2012) 1094-1106. doi:10.1016/j.energy.2012.01.062.

[8] I. Rafiqul, C. Weber, B. Lehmann, A. Voss, Energy efficiency improvements in ammonia production - Perspectives and uncertainties, Energy. 30 (2005) 2487-2504. doi:10.1016/j.energy.2004.12.004.

[9] T.T.D. Tran, A.D. Smith, Incorporating performance-based global sensitivity and uncertainty analysis into LCOE calculations for emerging renewable energy technologies, Appl. Energy. 216 (2018) 157-171. doi:10.1016/j.apenergy.2018.02.024.

[10] G. Di Lullo, H. Zhang, A. Kumar, Evaluation of uncertainty in the well-to-tank and combustion greenhouse gas emissions of various transportation fuels, Appl. Energy. 184 (2016) 413-426. doi:10.1016/J.APENERGY.2016.10.027.

[11] J. Yuan, S.H. Ng, W.S. Sou, Uncertainty quantification of CO2 emission reduction for maritime shipping, Energy Policy. 88 (2016) 113-130. doi:10.1016/J.ENPOL.2015.10.020.

[12] J. Yuan, S.H. Ng, Emission reduction measures ranking under uncertainty, Appl. Energy. 188 (2017) 270-279. doi:10.1016/j.apenergy.2016.11.109.

[13] T. Fleiter, D. Fehrenbach, E. Worrell, W. Eichhammer, Energy efficiency in the German pulp and paper industry - A model-based assessment of saving potentials, Energy. 40 (2012) 8499. doi:10.1016/j.energy.2012.02.025.

[14] S. Moret, V. Codina Gironès, M. Bierlaire, F. Maréchal, Characterization of input uncertainties in strategic energy planning models, Appl. Energy. 202 (2017) 597-617. doi:10.1016/j.apenergy.2017.05.106.

[15] Q. Deng, X. Jiang, Q. Cui, L. Zhang, Strategic design of cost savings guarantee in energy performance contracting under uncertainty, Appl. Energy. 139 (2015) 68-80. doi:10.1016/j.apenergy.2014.11.027.

[16] E.T. Lau, Q. Yang, L. Stokes, G.A. Taylor, A.B. Forbes, P. Clarkson, et al., Carbon savings in the UK demand side response programmes, Appl. Energy. 159 (2015) 478-489. doi:10.1016/j.apenergy.2015.08.123.

[17] Y. Han, Z. Geng, Q. Zhu, Y. Qu, Energy efficiency analysis method based on fuzzy DEA cross-model for ethylene production systems in chemical industry, Energy. 83 (2015) 685695. doi:10.1016/j.energy.2015.02.078.

[18] T. Nauclér, P.-A. Enkvist, Pathways to a low-carbon economy: Version 2 of the global greenhouse gas abatement cost curve, 2009. doi:10.1016/j.enpol.2010.01.047.

[19] H.-M. Henning, A. Palzer, Energiesystem Deutschland 2050, Freiburg, 2013. doi:10.1016/j.jpowsour.2016.06.076.

[20] N. Gerhardt, F. Sandau, A. Scholz, H. Hahn, P. Schumacher, C. Sager, et al., Interaction renewable electricity, heat and transport [In German: Interaktion EE-Strom, Wärme und Verkehr], 2015. https://www.energiesystemtechnik.iwes.fraunhofer.de/content/dam/iwesneu/energiesystemtechnik/de/Dokumente/Veroeffentlichungen/.

[21] F. Kesicki, P. Ekins, Marginal abatement cost curves: a call for caution, Clim. Policy. 12 (2012) 219-236. doi:10.1080/14693062.2011.582347.

[22] F. Kesicki, Marginal Abatement Cost Curves: Combining Energy System Modelling and Decomposition Analysis, Environ. Model. Assess. 18 (2013) 27-37. doi:10.1007/s10666-0129330-6.

[23] J. Palm, P. Thollander, An interdisciplinary perspective on industrial energy efficiency, Appl. Energy. 87 (2010) 3255-3261. doi:10.1016/j.apenergy.2010.04.019.

[24] P. Markewitz, G. Stein, Das IKARUS-Projekt: Energietechnische Perspektiven für 
Deutschland, Forschungszentrum Jülich, 2003. http://juwel.fzjuelich.de:8080/dspace/bitstream/2128/348/1/Umwelt_39.pdf.

[25] F. Bühler, A. Guminski, A. Gruber, S. von Roon, B. Elmegaard, Energy Saving Potential, Costs and Uncertainties in the Industry: A Case Study of the Chemical Industry in Germany, in: Proc. ECOS 2017 30th Int. Conf. Effic. Cost, Optim. Simul. Environ. Impact Energy Syst., San Diego, USA, 2017. http://orbit.dtu.dk/en/publications/energy-saving-potential-costs-anduncertainties-in-the-industry-a-case-study-of-the-chemical-industry-in-germany(8ce81d945394-4699-babd-0488761fa8c5)/export.html.

[26] M. Blesl, A. Kessler, Energieeffizienz in der Industrie, Springer Berlin Heidelberg, Berlin, Heidelberg, 2013. doi:10.1007/978-3-642-36514-0.

[27] International Energy Agency, Tracking Industrial Energy Efficiency and CO2 Emissions, Paris, 2007. doi:10.1787/9789264030404-en.

[28] The Institute for Industrial Productivity, Indusrial Efficiency Database: Ammonia, (n.d.). http://ietd.iipnetwork.org/content/ammonia\#technology-resources (accessed January 27, 2017).

[29] Statistisches Bundesamt (Destatis), Daten zur Energiepreisentwicklung - Lange Reihen von $\begin{array}{lllll}\text { Januar } & 2000 & \text { bis } & \text { November } & 2016,\end{array}$ https://www.destatis.de/DE/Publikationen/Thematisch/Preise/Energiepreise/Energiepreisent wicklungPDF_5619001.pdf?_blob=publicationFile (accessed December 15, 2017).

[30] K. Grave, M. Hazrat, S. Boeve, F. von Blücher, C. Bourgault, N. Bader, et al., Electricity costs of the energy intensive industry [In German: Stromkosten der energieintensiven Industrie], 2015. https://www.ecofys.com/files/files/ecofys-fraunhoferisi-2015-stromkosten-derenergieintensiven-industrie.pdf (accessed December 15, 2017).

[31] N. Metropolis, S. Ulam, The Monte Carlo Method, J. Am. Stat. Assoc. 44 (1949) 335-341. doi:10.1080/01621459.1949.10483310.

[32] G. Sin, K. V Gernaey, A.E. Lantz, Good modelling practice (GMoP) for PAT applications: Propagation of input uncertainty and sensitivity analysis, Biotechnol. Prog. 25 (2009) 10431053. doi:10.1021/bp.166.

[33] J.C. Helton, F.J. Davis, Latin hypercube sampling and the propagation of uncertainty in analyses of complex systems, Reliab. Eng. Syst. Saf. 81 (2003) 23-69. doi:10.1016/S09518320(03)00058-9.

[34] M.D. Mckay, R.J. Beckman, W.J. Conover, A Comparison of Three Methods for Selecting Values of Input Variables in the Analysis of Output From a Computer Code, Technometrics. 42 (2000) 55-61. doi:10.1080/00401706.2000.10485979.

[35] G. Sin, K. Gernaey, Data Handling and Parameter Estimation, in: M.C.M. van Loosdrecht, P.H. Nielsen, C.M. Lopez-Vazquez, D. Brdjanovic (Eds.), Exp. Methods Wastewater Treat., IWA Publishing Company, 2016: pp. 201-234.

[36] M.D. Morris, Factorial Sampling Plans for Preliminary Computational Experiments, Technometrics. 33 (1991) 161-174.

[37] A. Saltelli, M. Ratto, T. Andres, F. Campolongo, J. Cariboni, D. Gatelli, et al., Global Sensitivity Analysis: The Primer, John Wiley \& Sons, 2008. doi:10.1111/j.17515823.2008.00062_17.x.

[38] European Commission, Large Volume Inorganic Chemicals -Solida and Others Industry, 2007. http://eippcb.jrc.ec.europa.eu/reference/lvic-aaf.html.

[39] Federal Environmental Agency Germany, German Notes on BAT of the production of Large Volume Gaseous and Liquid Inorganic Chemicals, 2001.

[40] I.P. Prevention, Integrated Pollution Prevention and Control Large Volume Inorganic Chemicals - Ammonia, Acids and Fertilisers, I (2007).

[41] M. Aziz, A. Putranto, M.K. Biddinika, A.T. Wijayanta, Energy-saving combination of N2 
production, NH3 synthesis, and power generation, Int. J. Hydrogen Energy. 42 (2017) 2717427183. doi:10.1016/j.ijhydene.2017.09.079.

[42] E. Worrell, D. Phylipsen, D. Einstein, N. Martin, Energy use and energy intensity of the U.S. chemical industry, Berkeley, 2008.

[43] T.A. Currás, Barriers to investment in energy saving technologies Case study for the energy intensive chemical industry in the Netherlands, Universiteit Utrecht, 2010. ftp://ftp.ecn.nl/pub/www/library/report/2010/o10022.pdf.

[44] T. Ren, M. Patel, K. Blok, Olefins from conventional and heavy feedstocks: Energy use in steam cracking and alternative processes, Energy. 31 (2006) 425-451. doi:10.1016/j.energy.2005.04.001.

[45] T. Ren, M. Patel, K. Blok, Energy Efficiency and Innovative Emerging Technologies for Olefin Production, in: Proc. Eur. Conf. Energy Effic. IPPC Install., Vienna, 2004.

[46] C. Cui, J. Sun, X. Li, A hybrid design combining double-effect thermal integration and heat pump to the methanol distillation process for improving energy efficiency, Chem. Eng. Process. Process Intensif. 119 (2017) 81-92. doi:10.1016/j.cep.2017.06.003.

[47] European Commission, Best Available Techniques (BAT) Reference Document for the Production of Chlor-alkali, Luxembourg, 2014. doi:10.2791/13138.

[48] Eurostat, Statistical classification of economic activities in the European Community. NACE Rev. 2, 2008. doi:KS-RA-07-015-EN-N.

[49] R. Thakur, C. Vial, K. Nigam, Static mixers in the process industries-a review, \{... Res. Des. 81 (2003) 787-826. doi:10.1205/026387603322302968.

[50] J. Frutiger, J. Abildskov, G. Sin, Global sensitivity analysis of computer-aided molecular design problem for the development of novel working fluids for power cycles, Elsevier Masson SAS, 2016. doi:10.1016/B978-0-444-63428-3.50052-7.

[51] S. Brückner, S. Liu, L. Miró, M. Radspieler, L.F. Cabeza, E. Lävemann, Industrial waste heat recovery technologies: An economic analysis of heat transformation technologies, Appl. Energy. 151 (2015) 157-167. doi:10.1016/j.apenergy.2015.01.147. 